\title{
Dialogic Teaching - Investigating Teacher-Student Talk from a CA perspective
}

\author{
Béatrice Arend, Patrick Sunnen \\ University of Luxembourg, Esch-sur-Alzette, Luxembourg
}

\begin{abstract}
In this article we demonstrate how a CA based study can shed light on the complex phenomenon of classroom talk. Through a fine-grained single case analysis, it turns out that apparently 'disordered' moments in a French high school grammar lesson can be considered as an instance of dialogic teaching. We identify occurring overlaps and students' self-selections as accounts of dialogue promoting joint thinking and learning.
\end{abstract}

\section{Introduction}

\begin{abstract}
"It is worth considering what is implied when, after someone has asked you to make a decision, you reply, 'I'd like to talk it over first'. It's not that you expect that the talk will give you new information. It's rather that you know from experience that the matter in question can often appear quite differently as a result of talking it through. The situation and its priorities and implications can take a different shape, a different meaning. You may see connections that were not immediately apparent, or realise that some of the options might have results that need to be considered."
\end{abstract}

Douglas Barnes [1]

In this paper, our key concern is to raise teachers' awareness and their understanding of 'dialogic events' in the classroom. In this way, we intend to promote reciprocal and engaging classroom talk.

Over the last two decades, a considerable number of educational scholars have increasingly focused on talk to investigate thinking and learning in classroom settings. Many of them [2, 3, 4, 5, 6, 7, 8] draw on the bakhtinian concept of 'dialogism' to grasp the dynamics of classroom communication, in particular teacher-student talk. They rely on a sociocultural framework to emphasize the social and reciprocally dynamic dimensions of learning. Furthermore, they build on the intrinsically social and intersubjective nature of language to deal with forms of talk in the classroom and their role for the development of thinking and learning.

Adopting a 'dialogic' perspective means that speech utterances are not considered as isolated actions, but as mutually co-constructed interactions contextualised both by the objective(s) of the activity and by previous and following utterances. Bakhtin drew attention to the reciprocal dynamics of utterances in terms of 'responsive understanding'. The latter "is imbued with response and necessarily elicits it in one form or another: the listener becomes the speaker", and vice-versa; the speaker-listener "does not expect passive understanding", rather "he expects response, agreement, sympathy, objection, execution and so forth" [9].

From the researchers, who assume that the dialogic principle informs and extends our understanding of teaching and learning and who advocate bakhtinian theory to investigate classroom talk, we refer to Robin Alexander's approach to classroom education that he calls 'Dialogic Teaching' [2]. Working on audio and video data, he shows how talk can be used effectively by teachers to promote children's thinking and to initiate and support their learning. According to Alexander, 'dialogic' interactions are the ones in which teacher and students build on each other's ideas and "chain them into coherent lines of thinking and enquiry" [2]. In his view "such an approach leads to better intellectual engagement with what is being taught" [1].

Neil Mercer and Karen Littleton largely agree with Alexander when they describe 'dialogic teaching' as "that in which both teachers and pupils make substantial and significant contributions and through which children's thinking on a given idea or theme is helped to move forward" [4].

We should also note that 'dialogic teaching' differs from teacher-centred classroom practices in which teachers predominantly ask closed or known information questions: students are supposed to give the 'right' answer and then the teacher provides feedback [10]. These teacher-centred triadic pattern of teacher-student talk is also called IRF (input, response, feedback) sequence [11] (see also heading 2). However, 'dialogic teaching' pays as much attention to the students' talk as to the teacher's [12]. It reflects a view and depicts a practice where the teacher's perspective is not prioritised; teachers take into consideration students' contributions and all participants are co-developing the object of the ongoing lesson. 
Throughout this paper we will emphasize in a fine grained CA based analysis how a teacher and his students jointly engage in co-constructing ideas and, by that way, expand the teaching/learning object. We will analyse situated teacher-student interactions (unfolding in a French grammar lesson) which may appear 'disordered' at first sight and show how "forms in which reciprocity, exploration, speculation, argumentation (...) replace mere recall of predetermined responses" [13], enable students' involvement in developing new knowledge.

\section{Theoretical and methodological issues}

"Everything which occurs in the classroom requires the use of language. Crucially, it is through language in interaction that we access new knowledge, acquire and develop new skills, identify problems of understanding, deal with 'breakdowns' in communication, establish and maintain relationships and so on."

Steve Walsh [13]

We assume that analysing teacher-student talk allows us to enhance our understanding of thinking and learning processes occurring in the classroom. Furthermore, we assert that "the use of CA has much to offer" [15] to investigate teacher-student talk. Since "conversation analysis (CA) has been concerned with education from an interest in how educational practices are accomplished by participants as situated activities" [16], it grants an insight into classroom activity from the participants' perspective. Indeed, the systematic description of the turn-by-turn unfolding of teacher-student talk, "accomplished through repeated listening or viewing of audio or video recordings, have aided classroom researchers' understanding of the dynamics of talkin-interaction in classrooms and the social orders manifested therein" [17].

CA-informed studies of classroom talk [18] do not only point out that turn organisation in teacherstudent classroom talk is different from everyday conversation, they also reveal recurrent patterns of turn-taking displaying differential participation of teachers and students. Among the most frequently observed sequential (conversational) structures occurring in classroom, the three-part IRF sequences (input-response-feedback) [11] "are widely recognized and incorporated into classroom research" [17].

In the subsequent analysis we will discuss features of teacher-student talk which are divergent from the above mentioned recurrent patterns of ordered talk in classroom settings and so appear to be disordered. Relying on a CA based approach, we will study the dynamics of some 'disruptive' moments of situated classroom talk in a French grammar lesson. We will point out how the participants 'deviations' from prototypical teacher-centred three-part sequences (IRF) open up opportunities for the students to engage in a reciprocal process "in which ideas are bounced back and forth" [2] and on that basis taking forward thinking. A turn-by-turn analysis allows us to render visible accounts of 'Dialogic Teaching'-in-interaction as building on students' contributions to guide them toward a deeper understanding of the topic matter.

\section{Context}

To study talk-in-interaction in its sequential organisation as an emergent and interactional phenomenon, we rely on video data [19] which give access to a situated view of social conduct. The analysed excerpt is taken from the semi-improvised French drama film 'The Class' [20] that is based on the novel of the same name [21]. The novel is a semiautobiographical account of François Bégaudeau's experiences as a French language and literature teacher in a middle school in the $20^{\text {th }}$ arrondissement of Paris. Although the film is based on a screenplay, that follows the novel, it is often referred to as 'authentic' as the movie displays instances of classroom interactions in a rather realistic way. The analysed excerpt shows a teacher and his students during a French lesson discussing the correct use of subjunctive mood.

As the subjunctive mood is the subject matter unfolding in talk-in-interaction, we shall briefly address this critical grammatical issue. The subjunctive is a mood of verbs that can be found, with varying functions, in many languages. Generally, the notions that are expressed by the subjunctive are "doubt, possibility, necessity, desire and future time" [22]. In English the subjunctive mood is not very common whereas in French there are intricate rules of use behind 'that' (see figure 1), as well as rules of sequences of tenses that apply. In French grammar, the subjunctive remains a compulsory topic that carries many challenges, also for teachers.

In the discussed excerpt, students challenge the use of subjunctive mode and the related rules of sequences of tenses. We shall see that what is said is "reflected upon, discussed, even argued about, and the dialogic element lies partly in getting pupils themselves to do this" [2].

\section{Analysis}

In the following we will show how the students are doing organizing a 'new participation structure' differing from orderly IRF sequences. We shall point out and study dialogically co-constructed moments of classroom interaction in which student-initiated contributions, the participants (teacher and students) mutually orient to in responsive understanding, give rise to an expansion of the grammatical subject 
matter 'subjunctive mood', enhancing by that way the students' understanding of the treated topic. This becomes possible because the teacher's studentdirected talk provides opportunities for all participants to engage in a jointly organized and mutually constituted dialogic interaction based on the students' 'new' ideas and topic focused contributions.

\subsection{Doing organising IRF sequences}

At the beginning of the selected excerpt, teacher initiated IRF sequences lead to grammatically correct sentences written on the chalk board. They are meant to introduce the subjunctive mood and, more specifically, the use of the sequence of tenses (see sub-excerpt 1 and figure 1).
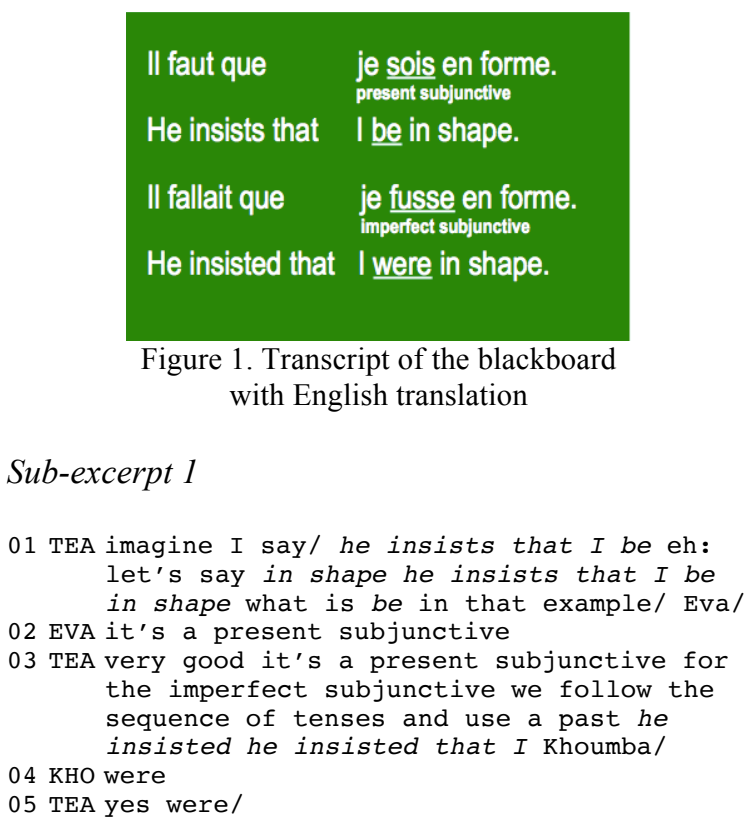

With regard to the turn-taking system, we can see in the above transcribed teacher-student talk (lines 1 to 5) that the 'next speaker self-selects' option' is not available to the students and that the 'current speaker selects next speaker' option is exclusively used by the teacher [23, 24] (lines 1 and 3).

Thus, in line 3 , there is no room for any student initiation after the teacher's "very good". Without orienting to potential student questions, the teacher immediately gives the next input and appoints the next speaker by calling her by her first name ('Khoumba'). Even if the teacher's explanations and

${ }^{1}$ Turn-taking is a locally managed, party administered and interactionally controlled system, sensitive to recipient design. Participants seek to achieve that one speaker talks at a time as well as to avoid gaps and overlaps. At the end of each turn, at the transition-relevance place (TRP), the current speaker may select the next speaker or the next speaker self-selects, or the current speaker continues. [24] his eliciting utterance are targeted at all students, the verbal selection of the next speaker prevents student self-selection.

The teacher here produces a "designedly incomplete utterance" [26] ("he insisted that/") to be completed by the addressed recipient's answer; Khoumba is carrying out the task (4). In line 5, the teacher then gives a positive feedback and marks the end of his turn (and of the sequence) by repeating the correct answer. In everyday conversation, in terms of TRP (transition relevance place), a transfer of speakership would be probable here but in classroom settings, a student-uttered next turn would be rather unusual after a turn (sequence) completion realized by the teacher. McHoul [25] pointed to asymmetric turn-allocation rights in teacher-student interaction in the sense that students may not self-select after each turn-completion point of the present speaker, but must wait to be selected by the teacher (especially in IRF 'scenarios'). Furthermore, students do not 'have the right' to select a next speaker after they complete their turn, the teacher is always the next speaker. There can be at most a conditioned form of student self-selection whereby the teacher addresses the whole group of the students to take a turn or bid for a turn [27].

\subsection{Moving out of IRF-designed sequences}

Walsh asserts that "in language classrooms, teacher control patterns of communication by managing both the topic of conversation and turntaking, while students typically take their cues from the teacher through whom they direct most of their responses" [14]. Thus, teachers, "through their unique status in the classroom, and by the power and authority they have, control both the content and procedure of a lesson, as well as controlling participation" [14].

In our case here, we can, however, observe a student (Esmeralda) self-selecting as the next speaker (6) without any delay. Esmeralda challenges the usage of the subjunctive mood as well as the related sequence of tenses. Her turn constitutes a kind of 'pivot' and prompts a shift in the participants' talk organization.

\section{Sub-excerpt 2}

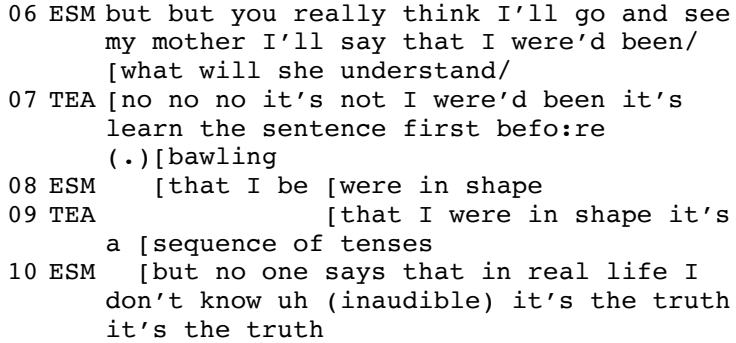


Esmeralda (6) opens up a discussion by addressing the teacher and by challenging the usefulness of the subjunctive mood in everyday life situations. By using twice the conjunction 'but', she designs the beginning of her turn to show that, whilst connected to what the teacher just said, "the upcoming turn will not be aligned with" and "will take a different stance" [28] from what the teacher stated. Esmeralda does not only challenge the grammatical form 'were', she defies the treated topic as such by putting it in a personally situated context. She claims that relying on the subjunctive imperfect when talking to her mother would inhibit shared understanding. Notice that she does not re-voice the verbal form correctly ("I were'd been"). By directly addressing the teacher ("but but you really think"), Esmeralda displays that she defies the teacher's representations about the subject matter as well as his authoritative voice [12]. In addition to starting with the coordinating conjunction 'but', marking an opposition to the prior turn (sequence) ${ }^{2}$, Esmeralda's turn construction reveals that she considers the teacher's ideas ("you think") as being opposed to her everyday activities ("I'll go and see my mother I'll say"). Besides providing accounts of a gap between the teacher's and her own position regarding the rules of sequence of tenses, Esmeralda states that the grammatical feature 'imperfect subjunctive' is no longer relevant when 'relocated' in a home context.

According to CA, interaction is context-shaped and context-renewing [14]. Thus, Esmeralda's contribution is dependent on previous ones and "subsequent contributions create a new context for later actions" [14]. Through the above mentioned accounts of opposition in her turn construction, Esmeralda counters the teacher's words as well as his participation management and, by the way, triggers 'going out of IRF device' to go for alternative interactional patterns. Also note that, in the manner Esmeralda addresses the teacher, she seeks confirmation from him: "what will she understand" may be considered as a rhetorical question already comprising the preferred anticipated answer ('nothing').

The teacher replies (7) by insisting on the correct wording of the verbal phrase. Since Esmeralda has not correctly re-voiced the verbal form, the teacher rejects her contribution ("no no no") as well as her grammatical phrasing ("it's not I were'd been"). He urges her to "learn the sentence first" and qualifies her objection as "bawling". The teacher is "cutting off' Esmeralda's line of argument and puts correct conjugation above contextualised sense making. Esmeralda (doing being a good student) goes immediately for a 'repair' (line 8) through reversing the order of phrases ("I were'd been" is reformulated

\footnotetext{
2 Note that the coordinating conjunction 'but' links phrases or clauses that are equal in importance and in structure.
}

in "I be were"). Then the teacher (consider also the truncation in line 7) utters the correct phrase ("I were in shape", line 9) and confirms its syntactic validity in terms of grammatical metalanguage ("it's a sequence of tenses").

In classroom settings, especially during IRF designed lessons, teacher-student interaction is mainly organized in recognizable ordered flows of talk (see lines 1-5) "and there have to be smooth transitions and clearly defined expectations if meanings are to be made explicit" [14]. In lines 6 to 11 , however (as in further transcribed talk, see subexcerpt 3 ), we can observe multiple instances of overlap breaking the 'one party speaking at a time' rule. However, extended episodes of overlapping talk, which may seem disordered, can "provide some of the most remarkable displays of fine-grained orderliness in conversation" [29].

Thus, in our excerpt, overlap occurs in lines 6 and 7 when the teacher intervenes near what may be projected to be a TRP at the end of Esmeraldas first syntactically complete turn unit. The teacher replies above all to the student's verbal phrasing and initiates a repair while Esmeralda extends the turn by another (sentence) unit ("what will she understand/"). Then, the overlap in lines 7 and 8 is a case of turn-terminal overlap similar to the previous one. The teacher lengthens the final sound of 'before' and then makes a pause, in this way suspending turn completion. Esmeralda performs the requested 'repair' at a point of possible, though not actual, completion within the teacher's turn. At line 9 the teacher makes an incursion into Esmeraldas turn. At the point where the teacher 'breaks into' the student's turn, Esmeraldas 'error' is predictable, the teacher is already able to recognize what Esmeralda is saying. Thus, he produces the 'right' verbal phrase, i.e. he goes for repair and correct formulation. Here, the "recognitional" overlap "clearly involves one participant closely monitoring another's talk" and promotes "the progress of the action embodied in the talk" [29]. The immediately following overlap at lines 9 and 10 can be considered as simultaneously performed verbal utterances displaying the teacher's and Esmeralda's opposite (contrary) representations regarding language and language use.

In line 10, through the re-use of the coordinating conjunction 'but', Esmeralda voices once again her resistance to the teacher's explanations of the subjunctive mood. She expands her line of argument: Not only her mother would have difficulties to understand 'the spoken imperfect subjunctive', "but no one says that in real life"! Esmeralda makes no attempt at repeating the grammatical phrase. Rather than simply re-vocalising the teacher's words or accepting abstract linguistic notions, she further develops her argument. Esmeralda's reply (10) is an account of both her critical stance and her responsive 
understanding towards the teacher. The overlap is not 'interruptive' in the sense of a breaching moment. Instead, we assume that the overlap, i.e., the synchronic uttering of the phrases "sequence of tenses" and "but no one says that in real" is the verbal instantiation of dialogically crossing perspectives: scholastic metalanguage 'meets' everyday communication, authoritative discourse (the teacher's voice) 'meets' internally persuasive discourse (Esmeralda's voice) in mutual attention [12].

In our analysis of the preceding subsequence, we had a closer look at how the teacher and Esmeralda are re-organizing classroom talk and the social orders manifested therein (going from rigid rule governed turn taking procedures to student-initiated discussion). Esmeralda's 'pivot' turn (6) is 'kickstarting' the restructuring of the participation framework. We want to point out that what initially appears to be the student's individual achievement is in fact co-constructed with the teacher in reciprocal commitment. The student seizes the opportunity at the appropriate juncture and gains access to the floor (6) after the IRF sequence [11]. Even though the teacher's replies (in lines 7 and 10) show his disapproval of the discussion, he will nevertheless provide a space for further dialogue and co-"embark upon a move out of the IRF" [23]. In the following teacher-student interaction the question of who is to speak will be less rigid.

Furthermore, we shed light on overlaps as accounts of a dialogically co-constructed teacherstudent talk. With regard to classroom dialogue, we should also emphasize here the temporal dimension of the sequential unfolding of talk: overlapping contributions display that "the word in living conversation is directly, blatantly, oriented toward a future answer-word: it provokes an answer, anticipates it (...). Forming itself in an atmosphere of the already spoken, the word is at the same time determined by that which has not yet been said but which is needed and in fact anticipated by the answering word. Such is the situation with any living dialogue. The orientation towards an answer is open, blatant and concrete" [30]

\subsection{Doing appropriating "it"}

After Esmeralda's 'pivot' question (echoed in her extending argument, see sub-excerpt 2), breaking with the bounded IRF sequences, the floor is open for other participants' comments and questions. Thus, in the follow-up of the analyzed dialogic event, we identify some 'competitive' overlaps [31] in which the teacher and the students compete for turns in progress. Besides inaudible contributions, there is some 'hubbub' and laughter in the classroom during which the teacher tries to return to the 'essentials' of the French lesson: he seeks to ensure the acknowledgment of the authority of grammar.

Then Angelica self-selects (see transcription below, line 11) to launch a longer statement. Her "utterance is related not only to preceding, but also to subsequent links in the chain of speech communication" [9] and is produced (such as all utterances produced in living speech) with a situated evaluative accent. Angelica addresses the teacher by showing agreement with previous student assertions. Beyond the evaluative orientation in her turn, Angelica 'upgrades' Esmeralda's argument with a time dimension to support the unsuitability of the imperfect subjunctive for everyday communication. She points to the 'outdated nature' of 'it' and assigns 'that' to a past era by arguing that even her grandmother "didn't' speak like that". Other participants will build on her idea (lines 12-19).

\section{Sub-excerpt 3}

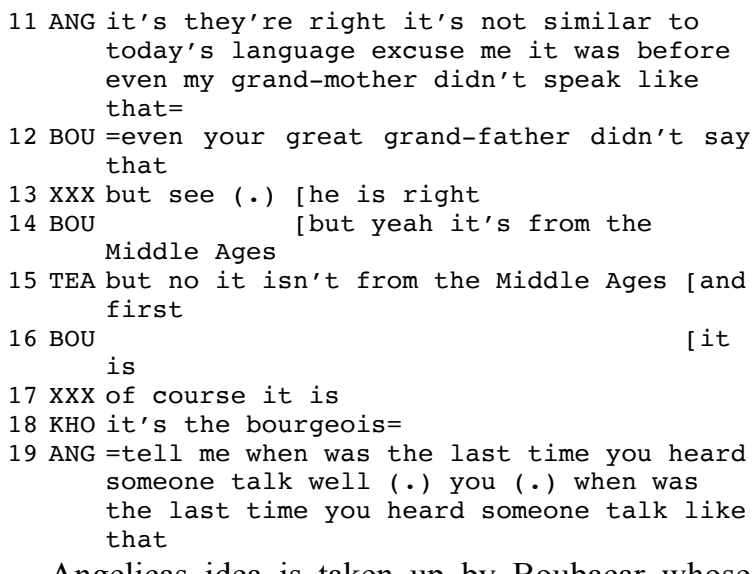

Angelicas idea is taken up by Boubacar whose turn ensues in latching (12). Boubacar's turn construction has an identical syntactic structure to Angelica's final TCU. Indeed, Boubacar recycles the phrasal structure of Angelica's turn completion and widens the temporal dimension to a more distant past ("great grand-father"). Notice here the use of the personal pronouns: Angelica's "my" (11) becomes Boubacar's "your" (12). Boubacar visibly transforms Angelica's argument into a joint one, though he does it from his point of view [12]. Then, another (unidentified) student self-selects and elicits participants' attention (13). Boubacar's following 'interruptive' turn-taking (14) and the occurring overlap can be considered as a mid-turn 'progressional' onset [31]. Boubacar promotes the progress of talk when he proceeds to speak at a potential transition point, i.e. the instant the current speaker makes a pause. Just like Esmeralda, he initiates his turn with 'but' to counteract the teacher's authoritative voice. Through simultaneously uttering the phrases 'he is right' and 'but yeah' the two speakers/listeners (lines 13 and 14) instantiate their respective points of view, i.e. 
their mutual commitment in the dialogic dynamics of overlapping talk. Furthermore, Boubacar strengthens the time argument by assigning 'it' to the Middle Ages. In the following the two students successively join their voices (lines 16 and 17) to reinforce their shared position against the teacher's rejection (15).

Then Khoumba self-selects (18) and provides an expanding contribution: she asserts the 'bourgeois' nature of 'it', thus adding a social dimension to the discussed matter. In the next turn, Angelica addresses the teacher 'urging' him to provide an account of a self-experienced real life event in which he "heard someone talk like that".

We should underline here the repeated use of the indexical terms "it" (8 times) and "that" (3 times) in the transcribed speech. The students do not refer to the subject matter by its specific name. What do the students refer to when they use 'it' and 'that'? Do they share a similar concern? We assume that the participating students reciprocally inform each other's understanding of the use of the imperfect subjunctive and by that way co-construct a joint focus of attention: the referent is assigned and displayed on the chalk board and has been uttered several times by the teacher ("that I were in shape, it's a sequence of tenses"). The students jointly engage in defending a shared idea without correctly vocalising the grammatical item: no one speaks like 'that', regardless of 'it's grammatical or metalinguistic designation. Through tracking the indexical terms 'it' and 'that' in their sequential occurrences, we can show how the students dialogically 'move forward' in attempting to draw a sense-making connection between grammatical forms/linguistic metalanguage and authentic talk in real life. By their mutually co-constructed attempts of contextualising a 'strange' verbal form, the students are approaching the subject matter 'correct use of imperfect subjunctive'; they are doing appropriating 'it'.

\section{Conclusion}

In the presented 'single case' study, we shed light on a dialogic event in a French Language classroom from a CA perspective, which allows to make a finegrained analysis of interactional stances. We emphasize that teacher-student talk is a very complex sequentially unfolding process accomplished in the situated, mutually addressed utterances of the teacher and the students. At times the teacher and the students engage in a rather structured and teachercentered classroom talk which can be identified as IRF sequences offering little space for spontaneous student contributions or questions. But, we can also identify occasions in which students re-organize the participation framework in mutual commitment with the teacher. What at first sight might be considered as disordered, reveals itself, in a CA-oriented analysis, as jointly organized.

In our analysis we point out how students launch moving out of IRF sequences by that way 'designing' a new more open participation modus. CA also allows us to conduct a close analysis of turn allocation. Turn taking (in terms of self-selection or overlaps) is indeed relevant for studying the students' contributions in their social dynamics of responsive understanding. Through the analysis of occurring overlaps, for example, we can highlight how the teacher and the students are anticipating the others' utterances, that and how they are oriented to the other. Indeed, the occurring overlaps and selfselections are accounts of mutual attention and accounts of dialogue in terms of "holding different perspectives in tension" [32]. Even though the teacher does not align himself with the students' arguments, he provides a space in which students "can actively test their understanding against that of others, and may use arguments to elicit relevant information and explanations" from the teacher and the other students "about what they perceive - and what they want to know" [33].

\section{Transcript conventions}

Talk was described according to conventions commonly used in Conversation Analysis.

\begin{tabular}{|c|c|}
\hline ALREADY & salient talk \\
\hline[ & overlapping talk \\
\hline$=$ & latching \\
\hline : & $\begin{array}{l}\text { extension of the sound or the } \\
\text { syllable it follows }\end{array}$ \\
\hline ' & rising intonation \\
\hline
\end{tabular}

Participants:

$\begin{array}{ll}\text { ESM } & \text { Esméralda } \\ \text { BOU } & \text { Boubacar } \\ \text { KHO } & \text { Khoumba } \\ \text { ANG } & \text { Angelica } \\ \text { TEA } & \text { Teacher } \\ \text { XXX } & \text { non-identified participant }\end{array}$

\section{References}

[1] Barnes, D. (2010) 'Why Talk is Important', English Teaching: Practice and Critique 9(2), pp. 7-10.

[2] Alexander, R. (2004) 'Towards Dialogic Teaching: Rethinking Classroom Talk', Dialogos, Cambridge.

[3] Maybin, J. (2006) 'Children's Voices. Talk, Knowledge and Identity', Palgrave Macmillan, London.

[4] Mercer, N. and Littleton, K. (2007) 'Dialogue and the Development of Children's Thinking', Routledge, London. 
[5] Tannen, D. (2007) 'Talking Voices. Repetition, Dialogue and Imagery in Conversational Discourse', Cambridge University Press, Cambridge.

[6] Walsh, S. (2006) 'Investigating Classroom Discourse', Routledge, London.

[7] Wegerif, R. (2008) 'Dialogic or Dialectic? The Significance of Ontological Assumptions in Research on Educational Dialogue', British Educational Research Journal 34(3), pp. 347-361.

[8] Wegerif, R. (2011) 'Towards a Dialogic Theory of How Children Learn to Think', Thinking Skills and Creativity 6(3), pp. 179-190.

[9] Bakhtin, M. (1986) 'Speech Genres and Other Late Essays’, University of Texas Press: Austin.

[10] Mehan, H. (1979) 'Learning Lessons', Harvard University Press, Cambridge.

[11] Sinclair, J. M. and Coulthard, M. (1975) 'Towards an analysis of discourse: The English used by teachers and pupils', Oxford University Press, London.

[12] Arend, B. and Sunnen, P. (2016) 'Dialogic Classroom Talk - Rethinking 'Messy' Classroom Interaction', in Proceedings of the $10^{\text {th }}$ Conference of the European Association for Practitioner Research on Improving Learning in Education and Professional Practice (EAPRIL), pp. 424-434.

[13] Alexander, R. (2012) 'Improving Oracy and Classroom Talk in English Schools: Achievements and Challenges'. Extended and referenced version of a presentation given at the Department for Education (DfE) seminar on Oracy, the National Curriculum and Educational Standards, 20 February 2012; http://www.robinalexander.org.uk/wp-

content/uploads/2012/06/DfE-oracy-120220-AlexanderFINAL.pdf (10 January 2016).

[14] Walsh, S. (2011) 'Exploring Classroom Discourse: Language in Action', Routledge: London.

[15] Walsh, S. (2013) 'Classroom Discourse and Teacher Development', Edinburgh, Edinburgh University Press.

[16] Koole, T. (2013) 'Conversation Analysis and Education', in Chapelle, C.A., 'The Encyclopedia of Applied Linguistics'. Blackwell Publishing.

[17] Mori, J. and Zuengler, J. (2008) 'Conversation Analysis and Talk-in-Interaction in Classrooms, in Martin, J., de Mejia, A.M. and Hornberger, N.H., 'Encyclopedia of Language and Education', Volume 3: Discourse and Education.

[18] McHoul, A. (1978) 'The Organization of Turns at Formal Talk in the Classroom', Language in Society 7(2), pp. 183-213.

[19] Mondada, L. (2009) 'Video Recording as the Reflexive Preservation and Configuration of Phenomenal Features for Analysis', in Knoblauch, H., Schnettler, B.,
Raab, J. and Soeffner, H.G., in 'Video Analysis: Methodology and Methods', Peter Lang, Frankfurt/Main, pp. 51-67.

[20] Cantet, L. (2008) 'Entre les Murs' [Motion Picture], Haut et Court.

[21] Bégaudeau, F. (2006) 'Entre les Murs', Editions Verticales, Paris.

[22] Encyclopaedia Britannica (2016), 29 January 29 2016, http://academic.eb.com.proxy.bnl.lu/EBchecked/topic/391 $224 / \operatorname{mood}$.

[23] Waring, H.Z. (2009) 'Moving out of IRF (InitiationResponse-Feedback): A Single Case Analysis', Language Learning 59(4), 796-824.

[24] Sacks, H., Schegloff, E.A. and Jefferson, G. (1974), 'A simplest systematics for the organisation of turn taking in conversation', Language 50(4), pp. 596-735.

[25] McHoul, A.W. (1985) 'Two aspects of classroom interaction: Turn-taking and correction', Australian Journal of Human Communication Disorders 13 (1), pp. 53-64.

[26] Koshik, I. (2002) 'Designedly Incomplete Utterances: A Pedagogical Practice for Eliciting Knowledge Displays in Error Correction Sequences', Research on Language and Social Interaction 35(3), pp. 277-309.

[27] Mazeland, H. (1983) 'Sprecherwechsel in der Schule', in Ehlich, K. and Rehbein, J., 'Kommunikation in Schule und Hochschule. Linguistische und ethnomethodologische Analysen', Günter Narr Verlag, Tübingen.

[28] Drew, P. (2013), 'Turn Design', in Sidnell, J. and Stivers, T., 'The Handbook of Conversation Analysis', Wiley-Blackwell, pp. 131-149.

[29] Sidnell, J. (2010) 'Conversation Analysis: A Introduction'. Wiley-Blackwell, Oxford.

[30] Bakhtin, M.M. (1981) 'The Dialogic Imagination'. University of Texas Press, Austin.

[31] Jefferson, G. (1983) 'Notes on some orderliness of overlap onset', in D'Urso, V. and Leonardi, P., 'Discourse analysis and natural rhetoric', Cleup Editore, Padua, pp. 11-38.

[32] Wegerif, R. (2010) 'Mind Expanding. Teaching for Thinking and Creativity in Primary Education', Open University Press/McGraw Hill, Buckingham.

[33] Mercer, N. (2002) 'Developing Dialogues', in Wells, G. and Claxton, G., 'Learning for Life in the $21^{\text {st }}$ Century. Sociocultural Perspectives on the Future of Education', Blackwell, Oxford. 